\title{
Storm surge in the Adriatic Sea: observational and numerical diagnosis of an extreme event
}

\author{
L. Zampato ${ }^{1}$, G. Umgiesser ${ }^{2}$, and S. Zecchetto ${ }^{3}$ \\ ${ }^{1}$ Istituzione Centro Previsioni e Segnalazioni Maree - Comune di Venezia, Venice, Italy \\ ${ }^{2}$ Istituto di Scienze Marine ISMAR-CNR, Venice, Italy \\ ${ }^{3}$ Istituto di Scienze dell'Atmosfera e del Clima ISAC-CNR, Padua, Italy
}

Received: 28 October 2005 - Revised: 15 June 2006 - Accepted: 30 June 2006 - Published: 19 September 2006

\begin{abstract}
Storm surge events occur in the Adriatic Sea, in particular during autumn and winter, often producing flooding in Venice. Sea levels are forecasted by numerical models, which require wind and pressure fields as input. Their performances depend crucially on the quality of those fields. The storm surge event on 16 November 2002 is analysed and simulated through a finite element hydrodynamic model of the Mediterranean Sea. Several runs were carried out, imposing different atmospheric forcings: wind fields from ECMWF analysis, high resolution winds from the limited area model LAMI and satellite observed winds from QuikSCAT (NASA). The performance of the hydrodynamic model in each case has been quantified. ECMWF fields are effective in reproducing the sea level in the northern Adriatic Sea, if the wind speed is enhanced by a suitable multiplying factor. High resolution winds from LAMI give promising results, permitting an accurate simulation of the sea level maxima. QuikSCAT satellite wind fields produce also encouraging results which claim, however, for further research.
\end{abstract}

\section{Introduction}

The Adriatic Sea is a semi-enclosed sea, extending about $1000 \mathrm{~km}$ by $200 \mathrm{~km}$ and entirely surrounded by mountain chains. Particularly during autumn and winter, storm surge events occur in its northern part: the sea level rises to unusual values, because of the local low pressure system and of strong south-east sirocco wind channelled by orography. If such events occur in phase with the astronomical tide, they produce the flooding of the coastal regions and the phenomenon of high water in Venice.

Sea levels are forecasted by numerical models, which require wind and pressure fields as input. This study, which

Correspondence to: L. Zampato

(lucia.zampato@comune.venezia.it) uses the SHYFEM ${ }^{1}$ model developed at ISMAR-CNR of Venice, consists of a set of hindcast numerical simulations for November 2002, a month characterised by a severe storm surge event on day 16.

A crucial problem in the numerical modelling of the storm surge is the quality of the meteorological fields used as forcing: inaccuracies in these forcing terms propagate in the computation of the sea state. The aim of this paper is to evaluate the performance of the SHYFEM hydrodynamic model, when driven by different meteorological forcings. Three kinds of atmospheric input were considered: wind and atmospheric pressure analysis fields of the ECMWF global model, initialised every day through the run of the previous day and including a data assimilation scheme; wind and atmospheric pressure fields from the high resolution LAMI model, operational at the meteorological service ARPA of Emilia Romagna (Italy); winds observed by the satellite QuikSCAT (NASA) and atmospheric pressure analysis fields of the ECMWF global model.

In Sect. 2 the storm surge event on 16 November 2002 is described, according to the available observations. Section 3 is devoted to present the SHYFEM model, and to describe and discuss the different atmospheric inputs used in the simulations. Section 4 reports some conclusive remarks.

\section{The storm surge event on 16 November 2002}

The high water event occurred in Venice on 16 November 2002 was the fourth highest event even registered in the city: in the historical centre (Punta Salute) the water level reached $+147 \mathrm{~cm}$ on the local datum, flooding more than $90 \%$ of the city ground.

\footnotetext{
${ }^{1}$ Abbreviations: SHYFEM; Shallow water HYdrodynamic Finite Element Model, ISMAR; Istituto di Scienze MARine, CNR; National Council of Research, ICPSM; Istituzione Centro Previsioni e Segnalazioni Maree, ECMWF; European Centre for Medium-Range Weather Forecasts, LAMI; Limited Area Model Italy, ARPA; Agenzia Regionale Prevenzione e Ambiente.
} 
CNR Platform 11-20 November 2002

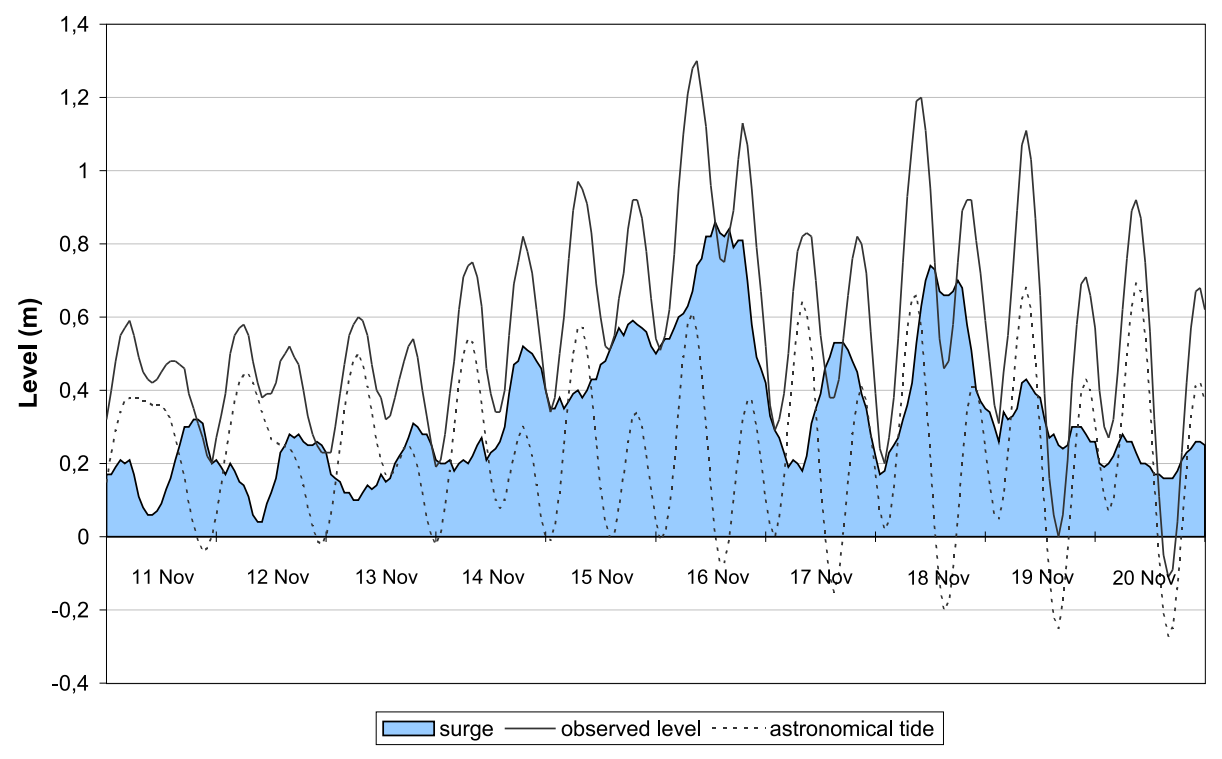

Fig. 1. Observed sea level at CNR platform, 11-20 November 2002: total level (solid line), astronomical tide (dashed line), surge (limit of the filled area).

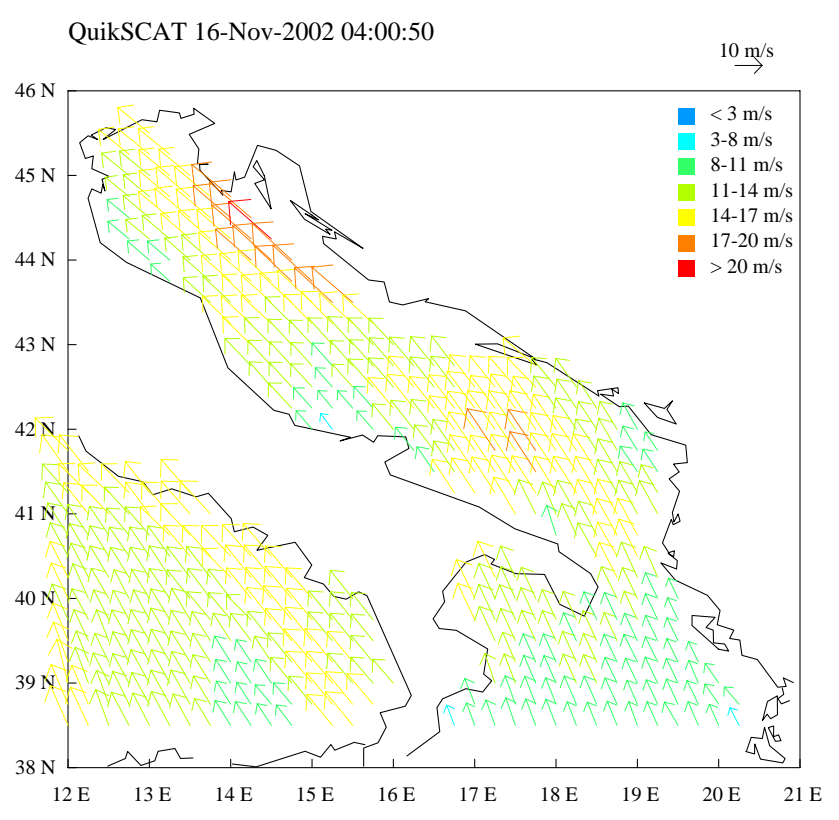

Fig. 2. Wind field over the Adriatic Sea observed by the QuikSCAT satellite on 16 November 2002 at 04:00 UTC.

Figure 1 shows the sea level measured in the Adriatic Sea, at the CNR platform $\left(45^{\circ} 18^{\prime} \mathrm{N}, 12^{\circ} 30^{\prime} \mathrm{E}\right)$, about $15 \mathrm{~km}$ offshore the Venice Lagoon, during the period 11-20 November. The total observed level (solid line) is decomposed in the astronomical tide (dashed line) and in the meteorological residual, or surge (limit of the filled area). The surge be- came relevant, over $+40 \mathrm{~cm}$, from the evening of 14 November and reached the maximum value of $86 \mathrm{~cm}$ on 16 November around 12:00 UTC. The maximum surge occurred at low astronomical tide.

The meteorological condition at the flooding time was characterized by a deep depression over the Gulf of Biscay which induced a pressure difference between the southern and northern Adriatic. The wind field observed at 04:00 UTC of the same day by the NASA's satellite QuikSCAT (Fig. 2), shows an intense sirocco wind over the whole Adriatic, with speeds reaching $20 \mathrm{~m} / \mathrm{s}$ along the Croatian coast.

The time series of pressure and wind, observed at the CNR platform and at several Adriatic coastal stations of the SYNOP network, show the persistence of a marked pressure difference between southern and northern Adriatic $(17 \mathrm{hPa}$ between Dubrovnik and Venice-Tessera on 16 November at 15:00 UTC) and of a strong sirocco wind over the whole basin (as to $22 \mathrm{~m} / \mathrm{s}$ at CNR platform and $24 \mathrm{~m} / \mathrm{s}$ at Termoli) in the period 14-16 November.

The strong correlation among surge and weather parameters, in particular the atmospheric pressure and the wind acting on the sea surface, is well known (Pugh, 1987). Local atmospheric pressure induces an inverse barometric effect, consisting in a rise of the water level when the atmospheric pressure diminishes. This effect can be roughly quantified in about $1 \mathrm{~cm}$ for $1 \mathrm{hPa}$ drop in pressure. The wind effect consists in a transfer of momentum from the atmosphere to the sea, through the friction at the air-water interface. This term, called wind stress, principally depends on the wind speed, but also on the structure of the atmospheric boundary layer and the wave field developed during the storm. Also the wind 
direction and the fetch, combined with the local geographic features of the basin, play an important role in generating the surge. In particular strong south-easterly winds (sirocco) over the Adriatic Sea, associated with the crossing of cyclones over the Mediterranean Sea, are effective in pushing the water toward the northern closed end of the basin and raising the sea level. The importance of sirocco wind in producing flooding events in Venice was evidenced by many authors (see for example Palmieri and Finizio, 1970; Tomasin and Frassetto, 1979; Canestrelli et al., 2001). The wind duration is also important, but its effect can not be simply quantified, because it has important consequences on the Adriatic seiches. The seiches are free oscillation of the Adriatic Sea, initially stimulated by meteorological factors and persisting, progressively attenuated, for several days, also after the storm has finished. Theoretic considerations and numerical experiments have shown that the development of the seiche, its amplification or attenuation, strongly depend on the duration of the wind, giving origin to the motion (Tomasin et al., 2005).

\section{Numerical simulations}

\subsection{The SHYFEM hydrodynamic model}

The Shallow-water HYdrodynamic Finite Element Model (SHYFEM), developed at ISMAR-CNR of Venice (Umgiesser et al., 2004), is operational at ICPSM since November 2002 (Canestrelli and Zampato, 2005). The 2-dimensional version of the model solves the vertically integrated shallow-water equations, in their linearized formulation with levels and transports. The model uses a semi-implicit time stepping scheme that does not restrict the time step with a stability criterion due to the fast moving gravity waves. The finite element approach allows to use variable size grids: the region of interest, in this case the northern Adriatic Sea, is represented with high spatial resolution (about $1.5 \mathrm{~km}$ ), maintaining a relatively coarse resolution $(30 \div 40 \mathrm{~km})$ in other areas of the Mediterranean.

For the purposes of this study, some simulations of the SHYFEM model were realized on the whole Mediterranean domain, others using a grid of the only Adriatic Sea.

The model is forced by the atmospheric pressure gradients and the wind stress $\tau$, which can be computed from the wind velocity $\boldsymbol{U}=(u, v)$ through: $\boldsymbol{\tau}=\left(\tau_{x}, \tau_{y}\right)=\rho_{a} C_{D}|\boldsymbol{U}|(u, v)$, where $u$ and $v$ are the zonal and meridional wind components, $\rho_{a}=1.225 \mathrm{~kg} / \mathrm{m}^{3}$ is the air density, kept constant in this study, and $C_{D}$ is the dimensionless drag coefficient. In this work $C_{D}$ has been parametrized in four different ways (labels between brackets indicate the name of the corresponding run with the SHYFEM model):

- a constant formulation: $C_{D}=2.5 \times 10^{-3}$ (run C);

- a commonly used formulation: $C_{D}=(0.630+0.066|\boldsymbol{U}|) 10^{-3}$ (run SB)

(Smith and Banke, 1975);
- a wave dependent formulation (run $\mathrm{W}$ ), whith $C_{D}$ computed by ECMWF, through the coupling between the atmospheric model and a wave model (Janssen, 1989; Persson, 2000);

- an atmospheric boundary layer dependent formulation (run BL), in which $C_{D}$ is computed from the wind speed, air temperature, sea surface temperature, air humidity, with an iterative procedure, supposing initial neutral stability atmospheric conditions (Liu et al., 1979).

The time step of the hydrodynamic model is $5 \mathrm{~min}$, which is a good compromise between the accuracy of the computations and the computational load. At every time step the model uses the above forcings and computes new values of the water levels and current speeds. The SHYFEM model's operation is represented in the flow chart in Fig. 3. Since the forcings (atmospheric pressure, wind) are only available every $6 \mathrm{~h}$, they are linearly interpolated in order to provide the model with a pressure and wind field at every time step.

\subsection{The atmospheric input}

\subsubsection{ECMWF atmospheric fields}

The ECMWF atmospheric general circulation model (Persson, 2000), based on the primitive equations, includes the effects of orography, a parametrization of boundary layer processes, a radiation scheme, cloud physics, a description of the hydrological cycle. The atmospheric model assimilates observations (both in-situ and satellite data) through a four dimensional variational system (4DVAR) and produces analysis and forecast fields. The analysis fields are computed by ECMWF at the synoptic hours 00:00, 06:00, 12:00, 18:00 UTC, comparing the available observations with a very short (6-h) forecast of the same model used for the operational forecast.

The third generation Wave Model WAM (WAMDIgroup, 1988) is integrated into the atmospheric model, allowing the computation of the two-way interaction between wind and waves.

The fields used in this work are the analysis fields of pressure at the mean sea level and the wind at $10 \mathrm{~m}$, over the Mediterranean Sea, computed by the version T511 (horizontal resolution of about $39 \mathrm{~km}$ ). They have been interpolated on a regular lat-lon grid with $0.5^{\circ}$ resolution for computational reasons.

\subsubsection{LAMI atmospheric fields}

The Limited Area Model Italy (LAMI) is the implementation of the Lokal-Modell (LM) developed at the Deutscher Wetterdienst (DWD) in the framework of the european Consortium for Small-scale MOdelling (COSMO) (Doms and Schattler, 2002). LM is a non-hydrostatic limited-area atmospheric model, based on the primitive thermo-hydrodynamic 


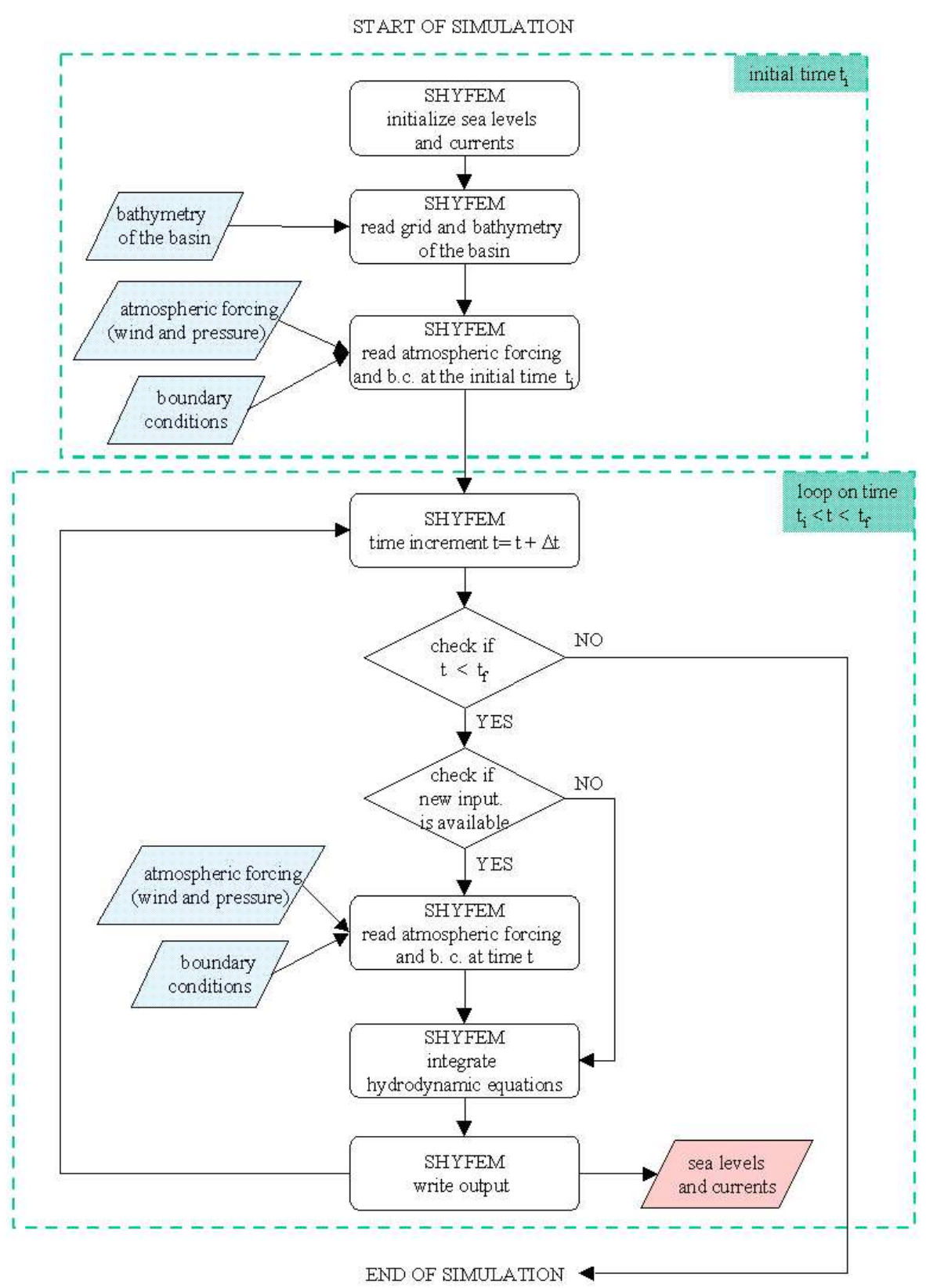

Fig. 3. Flow chart of the SHYFEM model: input data are represented in blue, output data in red.

equations describing compressible flow in a moist atmosphere. It uses rotated geographical coordinates and a generalized terrain-following vertical coordinate. The LAMI operational version has horizontal spatial resolution of $7 \mathrm{~km}$ and cover only the central part of the Mediterranean Sea. The fields used here were supplied by the Meteorological Service of Emilia Romagna (SMR-ARPA-EMR) that performs two operational runs every day, at 00:00 and 12:00 UTC, producing forecasted fields at time lags $+3,+6, \ldots,+72 \mathrm{~h}$. The boundary conditions for the limited area model are supplied by the general circulation atmospheric model (GME) of the DWD. To be imposed as forcing for the hydrodynamic model, LAMI fields were interpolated on a lat-lon grid with spacing of $10 \mathrm{~km}$.

Unfortunately, for the considered period of November 2002, data assimilation procedures were still not implemented in the LAMI model: as consequence, fields obtained from the LAMI operational forecast runs has been used to force the SHYFEM model.

\subsubsection{QuikSCAT satellite fields}

The scatterometer SeaWinds on board of the QuikSCAT satellite (NASA) provides wind fields over the oceans with a maximum spatial resolution of about $25 \mathrm{~km} \times 25 \mathrm{~km}$. 

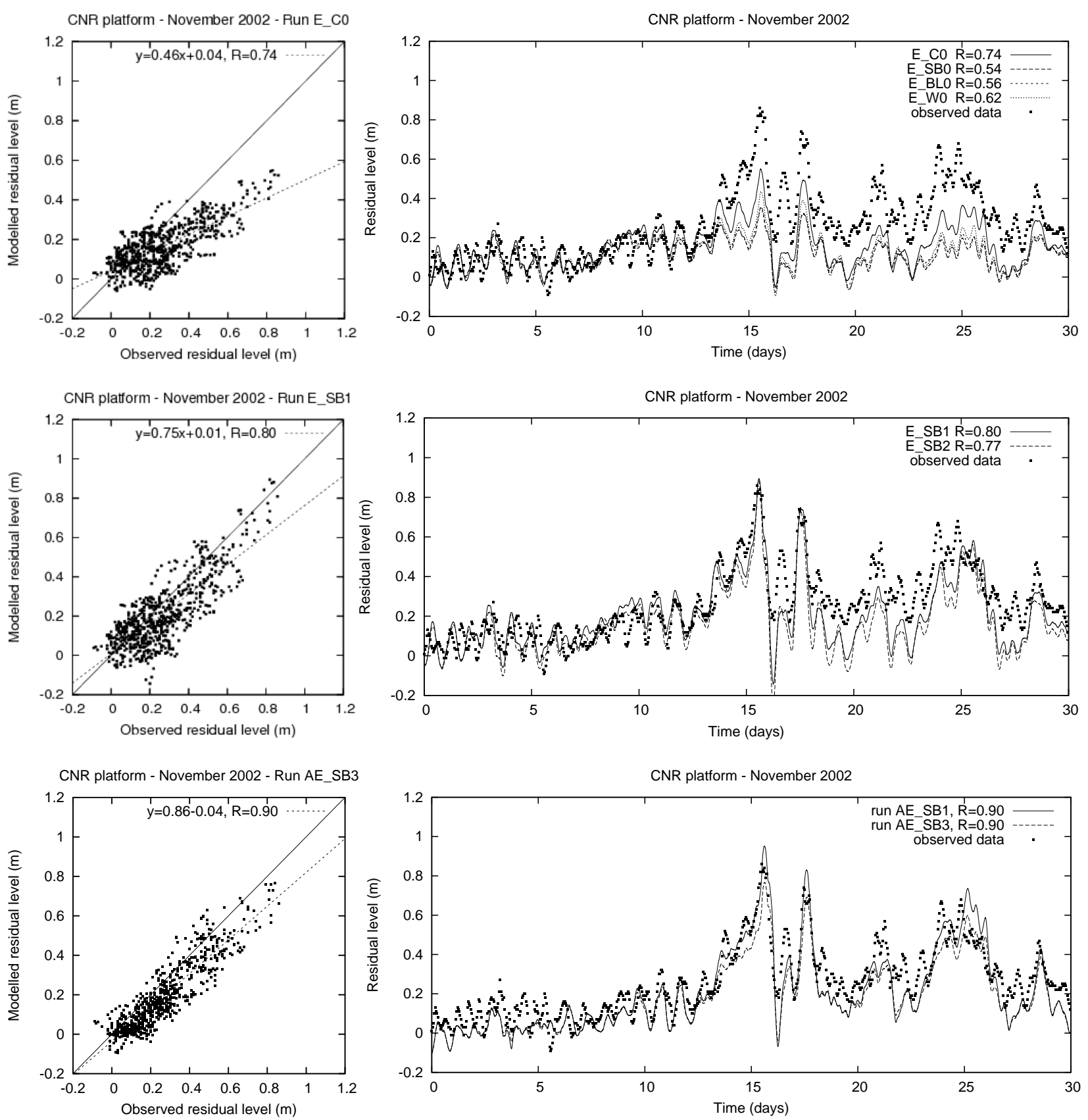

Fig. 4. Residual sea level at the CNR platform, November 2002. Dots represent observed data, lines show the values computed by the SHYFEM model, forced by ECMWF fields. Top panels: runs with different formulations of the wind stress. Middle panels: runs with multiplying correction factors. Bottom panels: runs with multiplying correction factors and observed sea level imposed as boundary conditions at Otranto.

It covers the Adriatic Sea on average twice a day, in the early morning and in the mid afternoon (approximately at 04:00 UTC and 17:00 UTC). For this reason, the satellite winds have been used along with the ECMWF fields, to obtain a data set suitable to drive the hydrodynamic model. ECMWF already assimilates the satellite wind data through its 4DVAR assimilation scheme. However, due to its coarser resolution with respect to the satellite fields, as well as to the intrinsic smoothing of the data carried out by any as- similation scheme (Cheŕuy et al., 2004), the wealth of information about the spatial variability provided by the satellite fields cannot be find out in the ECMWF analysis fields. This is the main reason why satellite and ECMWF winds have been used together, in spite of their intrinsic different nature. QuikSCAT data over the Adriatic Sea, when available, were simply inserted into ECMWF data over the Mediterranean Sea. At the other times, ECMWF data were used. Details on the adopted procedure are given in Canestrelli et al. (2003). 

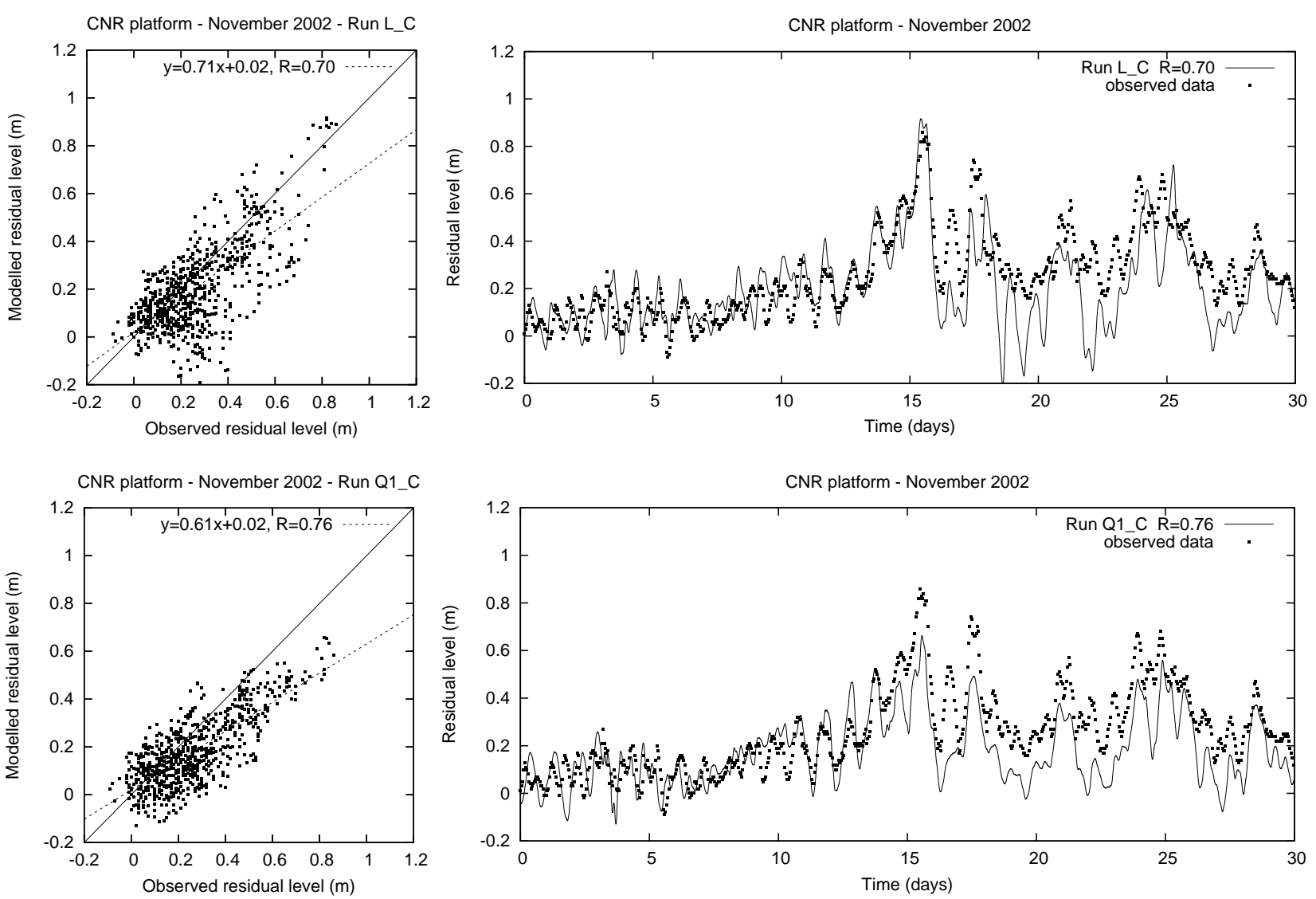

Fig. 5. Residual sea level at the CNR platform, November 2002. Top panels: runs with LAMI forcing and costant drag coefficient. Bottom panels: runs with QuikSCAT forcing and costant drag coefficient.

\subsection{Results and discussion}

A variety of runs have been realized forcing the hydrodynamic SHYFEM model by different data sources during November 2002.

A first set of runs was carried out with the model running in the Mediterranean Sea domain, driven by ECMWF fields. The different formulations of the wind stress term, listed in Sect. 3.1, were used and correction factors for the ECMWF wind speed were adopted. A second group of runs was realised with the SHYFEM model running in the Adriatic Sea domain, forced by LAMI fields. Finally, some runs were carried out forcing the model of the Mediterranean Sea by QuikSCAT wind fields integrated by the ECMWF fields to obtain a complete atmospheric input.

The results are presented in terms of the modelled and observed residual sea level time series at the CNR platform location, and of scatter diagrams. Fig. 4 shows the results of the runs with ECMWF forcing: the basic run E_C0, with constant drag coefficient (top panel of Fig. 4), yields sea level values strongly underestimated, but correlated with data $(R=0.74)$. The maximum surge on day 16 November is simulated with an error of $-31 \mathrm{~cm}$ and the bias, computed on the whole month, is $\bar{E}=-10 \mathrm{~cm}$. The other formulations of the wind stress term, even the most complex as the wave dependent or the boundary layer dependent, provide worse results (again in the top panel of Fig. 4). To compensate this strong underestimation, the ECMWF wind speed was enhanced, over the Adriatic Sea, in three ways: through a constant factor 1.5 (run E_SB1), as suggested by Cavaleri and Bertotti (1997), through a constant factor 1.35 , recently proposed by Cavaleri (personal communication, 2005), whose results are not shown in this paper, and through a spatially variable factor, given by the ratio between QuikSCAT and ECMWF in each grid point of the Adriatic, averaged on the whole month of November 2002 (run E_SB2). The results (middle panel of Fig. 4) show an evident improvement, both in the correlation $(R=0.80)$ and in the simulation of the sea level peak, even if a negative bias remains in the second half of the month.

Supposing that this bias could depend on a not perfect reproduction of the sea level in the Ionian Sea, we realized some runs with the two enhancing factors 1.5 (run AE_SB1) and 1.35 (run AE_SB3), using the model of the Adriatic only and imposing the observed sea levels at Otranto as boundary conditions. The results (bottom panel of Fig. 4) evidence an improvement with respect to the previous runs, both in the correlation $(R=0.90)$ and in the agreement with data dur- 

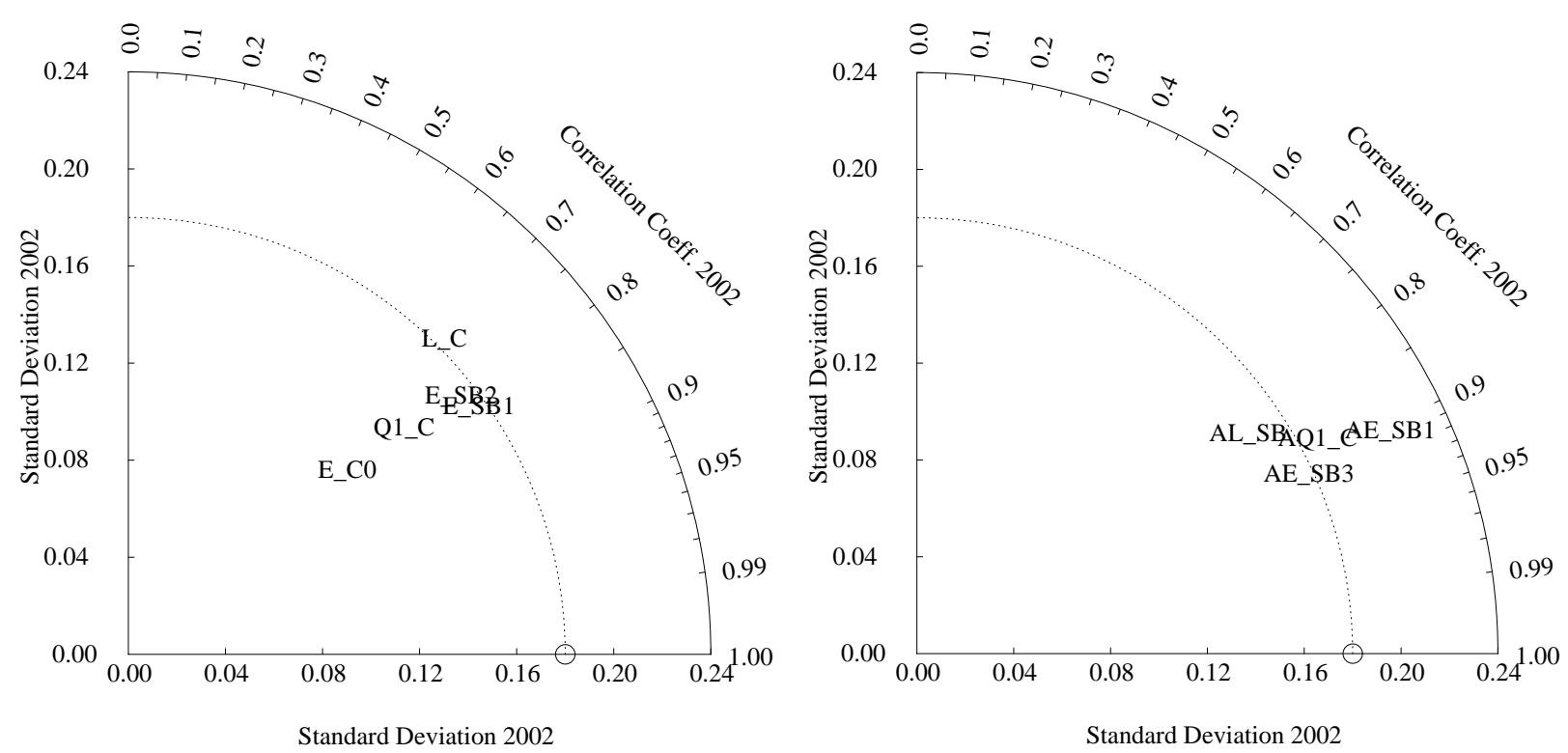

Fig. 6. Residual sea level at the CNR platform location, November 2002. Taylor diagram with results of the runs with different forcings. Left panel: runs without using observed sea levels. Right panel: runs with observed sea levels at Otranto, imposed as boundary conditions.

ing the second half of November (bias $\bar{E}=-5 \mathrm{~cm}$, in the run AE_SB1).

Some of the results obtained with LAMI and QuikSCAT forcing are shown in Fig. 5. Using the LAMI fields, the simulation of the surge peak on 16 November results accurate (top panel), without need of any enhancement of the wind field. Unfortunately, the modelled sea level shows a too high excursion with respect to the observed data. This can be due to the particular procedure used to construct the input for the hindcast simulation: it was obtained joining together LAMI fields, computed by different short forecast simulations. This procedure introduces discontinuities into the hydrodynamic model that might trigger and enhance seiches in the Adriatic Sea and create higher oscillations, than observed. As consequence, the correlation $(R=0.70)$ is lower than in the case of ECMWF forcing. The bias for the whole month is $\bar{E}=-6 \mathrm{~cm}$.

The results obtained forcing the SHYFEM model with QuikSCAT winds are encouraging. If compared with the results of the basic run E_C0 with ECMWF fields, the sea levels computed in the run Q1_C are more accurate $(R=0.76$, $\bar{E}=-8 \mathrm{~cm}$ ), but the surge peak of day 16 is underestimated by $20 \mathrm{~cm}$.

The Taylor diagrams in Fig. 6 summarize the performance of the SHYFEM model in the computation of the sea level during November 2002, obtained with the different forcings. The circle mark in the $\mathrm{x}$-axis, called reference point, represents the perfect fit between model results and data. The position of the labels, representing the results of the different runs, is determined by the values of the correlation $R$ and of the standard deviation of modelled data. Closer is a label to the reference point, better is the performance of the run. The best run without using observed sea levels at Otranto (see left panel of Fig. 6) is E_SB1, forced by ECMWF winds enhanced by a constant factor 1.5. Imposing observed sea level at Otranto as boundary conditions, generally improves the model performance (see right panel of Fig. 6). Again, the best results are obtained with enhanced ECMWF winds.

A significance test on the correlation $R$ between model results and observed data has been performed by means of the software R (http://www.cran.r-project.org). The computed correlation values resulted extremely significant, with a $\mathrm{p}$ value, calculated with the Pearson's test at a confidence level of $99 \%$, very close to 0 .

\section{Conclusions}

This paper intends to provide a contribution to the research on the sea level prediction in the Adriatic Sea, in particular for the city of Venice.

The finite element hydrodynamic model SHYFEM was used to simulate the storm surge in the Adriatic Sea. A set of numerical simulations of November 2002 has been carried out, imposing as input different wind fields, obtained from the global atmospheric model of ECMWF, from the regional atmospheric model LAMI and from the QuikSCAT satellite, searching for the best performance of the hydrodynamic model in reproducing the observed sea level. The goodness-of-fit of model results has been evaluated comparing them with observed sea level data measured in the open Adriatic Sea in terms of linear correlation $R$ and bias $\bar{E}$.

The analysis of results has shown that forcing the SHYFEM hydrodynamic model with ECMWF wind fields produce sea levels near Venice well correlated, but underestimated, with observations. Even sophisticated formulations 
of the wind stress term could not compensate this negative bias. The resulted levels are closer to the experimental data by applying correction factors to the wind speed.

Simulations driven by the regional model (LAMI) wind fields succeeded in simulating the storm surge, giving a good reproduction of the sea level peaks. Nevertheless the correlation with observed data was lower than in the case of ECMWF forcing and the modelled sea level showed marked oscillations. Results obtained forcing the SHYFEM model with satellite QuikSCAT wind fields integrated by ECMWF fields are fair, claiming for further research. They have shown that it is possible to manage satellite data in the hydrodynamic modelling, in spite of their distribution not always regular in space and time. For all the meteorological forcings, a marked improvement has been reached using the SHYFEM model only in the Adriatic Sea domain, with observed sea levels at Otranto imposed as boundary conditions.

Since this study was restricted to only one event, its conclusions do not pretend to have a general validity and cannot substitute a complete model output statistics that would require many years of data and model results, not available at present. Nevertheless, November 2002 could be taken as representative of the phenomenology bringing storm surge events, because of the high value of the sea level and the typicalness of the meteorological situation producing it. Moreover, it should be stressed that the almost totality of storm surge events in the Adriatic Sea occur in October and November. For this reason, the results of this work constitute a good test and can be useful in choosing the best meteorological input to drive hydrodynamic sea level models in the operational context. In fact the SHYFEM model is today operational at the ICPSM, centre for the tidal forecast of the Venice Municipality (Canestrelli and Zampato, 2005): it is forced by the ECMWF forecasted fields of pressure and wind and supplies every day the sea level prediction for the city of Venice.

The obtained results seem indicate that the simplest way to improve the sea level prediction in the Adriatic Sea consists in enhancing the ECMWF wind speed through a suitable multiplying factor. Nevertheless, since LAMI fields supply promising results, further studies and numerical simulations are planned to test their performance on more extended periods. The use of satellite observed winds in the operational context is limited both by their off-line availability and by their poor spatial and temporal coverages. However, because they provide interesting results, they will be included in the possible future developments, even if they could be used only in the initial spin-up phase of a forecast simulation. Finally, the important role played by the observed sea level at the Otranto Strait in improving the quality of simulations, stresses the necessity to develop effective data assimilation schemes.

Acknowledgements. The Authors especially want to thank A. Tomasin for the continuous support provided during this work. We acknowledge also G. Taroni for his help in improving the statistical methodology.
The satellite data have been downloaded from the web site http://podaac.jpl.nasa.gov/.

Edited by: V. Kotroni and K. Lagouvardos

Reviewed by: N. Prezerakos

\section{References}

Canestrelli, P. and Zampato, L.: Sea level forecasting at the Centro Previsioni e Segnalazioni Maree of the Venice Municipality, in: Flooding and Environmental Challenges for Venice and its Lagoon: State of Knowledge, edited by: Fletcher, C. and Spencer, T., pp. 85-97, Cambridge University Press, 2005.

Canestrelli, P., Mandich, M., Pirazzoli, P., and Tomasin, A.: Venti, depressioni e sesse: perturbazioni delle maree a Venezia (19512000), Tech. rep., CPSM-Centro Previsioni e Segnalazioni Maree, Comune di Venezia, Venice, Italy, 2001.

Canestrelli, P., Cucco, A., De Biasio, F., Umgiesser, G., Zampato, L., and Zecchetto, S.: The use of QuikSCAT wind fields in water level modeling of the Adriatic Sea, in: Proceedings of the Sixth European Conference on Applications in Meteorology ECAM 2003, Ufficio Generale per la Meteorologia-Aeronautica Militare Italiana, 2003.

Cavaleri, L. and Bertotti, L.: In Search of the Correct Wind and Wave Fields in a Minor Basin, Mon. Wea. Rev., 125, 1964-1975, 1997.

Cheŕuy, F., Speranza, A., Sutera, A., and Tartaglione, N.: Surface winds in the Euro-Mediterranean area: the real resolution of numerical grid, Ann. Geophys., 22, 4043-4048, 2004, http://www.ann-geophys.net/22/4043/2004/.

Doms, G. and Schattler, U.: A description of the nonhydrostatic regional model LM. Part I: dynamics and numerics, Tech. rep., Deutscher Wetterdienst, Offenbach, Germany, 2002.

Janssen, P.: Wave induced stress and the drag of the air-flow over sea wave, J. Phys. Oceanogr., 19, 745-754, 1989.

Liu, W., Katsaros, K., and Businger, J.: Bulk parameterization of air-sea exchanges of heat and water vapor including the molecular constraints at the interface, J. Atmos. Sci., 36, 1722-1735, 1979.

Palmieri, S. and Finizio, C.: The prediction of sea tides in Venice, STR 11, Istituto di Fisica dell'Atmosfera, Roma, 1970.

Persson, A.: User guide to ECMWF forecast products, Meteorol. Bull. M3.2, ECMWF, Reading, UK, 2000.

Pugh, D.: Tides, surges and mean sea level, Wiley, New York, 1987.

Smith, S. and Banke, E.: Variation of the sea surface drag coefficient with wind speed, Quart. J. Roy. Meteorol. Soc., 101, 665$673,1975$.

Tomasin, A. and Frassetto, R.: Cyclogenesis and forecast of dramatic water elevations in Venice, in: Marine Forecasting, edited by: Nihoul, J., pp. 427-437, Elsevier, Amsterdam, 1979.

Tomasin, A., Umgiesser, G., and Zampato, L.: On the dynamics of the Adriatic seiche, in: Scientific research and safeguarding of Venice. CORILA Research Programme 2001-2003. Volume III. 2003 results, edited by: Campostrini, P., pp. 65-74, Venice, 2005.

Umgiesser, G., Melaku Canu, D., Cucco, A., and Solidoro, C.: A finite element model for the Venice Lagoon. Development, set up, calibration and validation, J. Mar. Syst., 51, 123-145, 2004.

WAMDIgroup: The WAM model - A third generation ocean wave prediction model, J. Phys. Oceanogr., 18, 1775-1810, 1988. 